\title{
QUALIDADE VISUAL DA PAISAGEM DO PARQUE NATURAL MUNICIPAL TANGUÁ, CURITIBA - PR
}

\author{
Rogério Bobrowski ${ }^{1}$, Yury Vashchenko², Daniela Biondi ${ }^{3}$ \\ (recebido em 02.02.2010 e aceito para publicação em 10.06.2010)
}

\section{RESUMO}

A valoração da paisagem serve como instrumento prático e objetivo para o gerenciamento de parques urbanos: na avaliação e no manejo de impactos e para estabelecimento de Zonas de Amortecimento. Esta pesquisa foi planejada para analisar, valorar e classificar tecnicamente paisagens representativas de um parque municipal de Curitiba (PR), bem como, analisar a preferência dos visitantes em relação às paisagens. A metodologia criada para avaliação técnica consistiu em quantificar os elementos e componentes das paisagens, de acordo com os pesos estabelecidos, para valoração da qualidade visual da paisagem. As paisagens avaliadas foram agrupadas em três classes: $37,21 \%$ enquadraram-se na classe Baixa, 32,56\% na classe Média e 30,23\% na classe Alta. Observou-se uma diferença significativa ao nível de probabilidade de $1 \%$, tanto entre os valores de cada paisagem bem como entre as classes descritas. Houve preferência visual por paisagens sem urbanização e com maior visualização de um conjunto harmônico de elementos. A metodologia desenvolvida mostrou-se útil para conhecer os elementos predominantes e aqueles que depreciam a qualidade visual das paisagens da vizinhança e aquelas internas. A qualidade visual da paisagem total foi considerada boa e atrativa, mesmo com as ações antrópicas do entorno imediato. Recomenda-se cautela na ocupação da divisa oeste do parque.

Palavras-chave: estudo da paisagem, parques urbanos, gerenciamento de áreas verdes.

\footnotetext{
${ }^{1}$ Engenheiro Florestal, Secretaria Municipal do Meio Ambiente (Prefeitura de Curitiba-PR). Mestrando em Engenharia Florestal - UFPR, Curitiba-PR, e-mail: bobrowski roger@yahoo.com.br

${ }^{2}$ Engenheiro Florestal, MSc, Doutorando em Engenharia Florestal - UFPR, Curitiba-PR, e-mail: vashchenko01@yahoo.com.br

${ }^{3}$ Engenheira Florestal, Dra ${ }^{2}$, Professora Depto. Ciências Florestais, Universidade Federal do ParanáUFPR, Bolsista Produtividade em Pesquisa - CNPq, Curitiba-PR, e-mail: dbiondi@ufpr.br
} 


\section{LANDSCAPE VISUAL QUALITY OF TANGUÁ MUNICIPÁL NATURAL PARK, CURITIBA- PR}

\section{ABSTRACT}

Landscape evaluation is used as a practical and objective way to manage urban parks, in terms of impact evaluation and management and establishment of buffer zones. This research aimed at analyzing, evaluating and technically classifying landscape pictures of a municipal park in Curitiba (PR), and also at analyzing tourist preferences with regard to the landscapes. The methodology created for technical evaluation consisted on quantifies elements and components of landscape according to established weights in order to attribute a value to landscape visual quality. The evaluated landscapes were organized into three classes: $37.21 \%$ in Low Class, $32.56 \%$ in Medium Class, and $30.23 \%$ in High Class. A significant difference was observed on a probability level of $1 \%$ between the values attributed to each landscape as well as to described classes. There was a visual preference for landscapes without urbanization and with more visualization of a harmonic group of elements. The developed methodology proved to be useful to determine the predominant elements and those that devalue the visual quality of the park landscape and of its vicinity. The total landscape visual quality was considered good and attractive even with evidence of human interference in the immediate vicinity. Caution in building was recommended on the west border of the park.

Keywords: landscape study, urban parks, urban forest management. 


\section{INTRODUÇÃO}

De acordo com Pires (1993), os estudos e avaliações da paisagem variam desde uma simples descrição até uma classificação em unidades homogêneas; também, desde estudos de percepção visual até a determinação da qualidade e fragilidade visuais.

A valoração da paisagem permite analisar a necessidade de conservação de determinadas áreas objetos de estudo, bem como, permite promover um melhor planejamento para ocupação do território, com menores impactos negativos e maior harmonia do homem com o ambiente (MILANO, 1990; OLIVEIRA, 2003).

Marenzi (2000) afirmou que vários autores agruparam os distintos métodos de avaliação da paisagem em: diretos, indiretos e mistos. As distinções criadas foram baseadas na premissa de que a avaliação da paisagem tem uma forte tendência subjetiva, mas que pode ser estudada de forma objetiva.

No método direto toma-se por base a totalidade da paisagem, pela visualização local ou pelo uso de substitutos (fotos, slides, gravuras, etc), com valoração efetuada pelo público em geral ou especialistas (PIRES, 1993). No método direto insere-se a análise da qualidade visual da paisagem.

Para Marenzi (1996), os métodos de análise da qualidade visual da paisagem podem contribuir no elenco de informações para estudos de ecologia da paisagem, principalmente quando se almeja incluir conhecimentos do potencial turístico e de recreação, bem como, de impactos visuais causados pela transformação da paisagem, já que tais métodos conseguem representar as preferências paisagísticas. Bulut e Yilmaz (2008) complementaram dizendo que a avaliação da qualidade visual da paisagem tem se tornado um mecanismo importante para agregar informações necessárias ao planejamento da paisagem.

A análise e regulação da qualidade visual da paisagem são relevantes devido à crescente importância do ambiente visual para a sociedade e de sua relação com fatores econômicos (KAMICAITYTE-VIRBASIENE; JANUSAITIS, 2004), sendo, por isso, a atratividade de certas áreas associada à riqueza dos recursos visuais, naturais e culturais existentes (BULUT; YILMAZ, 2008). Esse fato foi enfatizado por Vieira et al. (2007, p.4) quando afirmaram que "o entendimento da escolha de paisagens pela presença de determinados elementos que compõem certos cenários ajuda a criar modelos de paisagens que têm mais afinidades com o homem".

Para Kamicaityte-Virbasiene e Janusaitis (2004) os fatores do ambiente são importantes tanto para os indicadores da Qualidade Visual da Paisagem quanto para a

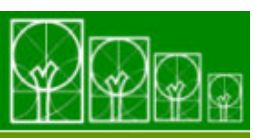

$\mathbf{S} \cdot \mathbf{B} \cdot \mathbf{A} \cdot \mathbf{U}$ Soc. Bras. de Arborização Urbana 
avaliação de preferência da Qualidade Visual pela sociedade envolvida (residentes e turistas).

Os parques urbanos são espaços públicos de dimensões significativas, com predominância de elementos naturais, principalmente cobertura vegetal, destinados ao lazer e à recreação (KLIASS ${ }^{4}$, citado por CASTELNOU NETO, 2006). Devido a isso, segundo Kaick et al. (2006), possuem diversas qualidades e promovem a efetivação de diversos benefícios (proteção de remanescentes de floresta nativa, pesquisa científica, culto às tradições da região, estruturação de atrativos turísticos, etc).

Curitiba, devido à sua condição de cidade modelo em termos ecológicos, acaba recebendo a visita de grande contingente de turistas em seus parques urbanos.

A implantação dos parques urbanos em Curitiba tem atendido a causas variadas, desde ambientais e ecológicas até as alternativas de lazer e atrativo turístico (MENEZES, 1996).

Nesse contexto, pode-se dizer que paisagem e turismo são duas realidades intimamente relacionadas, pois a viagem turística é feita com o objetivo de romper com a rotina, sendo a paisagem o fator dessa mudança porque se constitui na expressão espacial e visual dos lugares (PIRES, 2001; PIRES, 2005).

Assim, este trabalho teve como objetivo geral avaliar a qualidade visual da paisagem de um parque municipal e do seu entorno a fim de conhecer os impactos visuais das paisagens existentes, e para isso os objetivos específicos foram:

a) Analisar, classificar tecnicamente e valorar fotografias representativas das paisagens existentes no parque;

b) Analisar a preferência dos visitantes em relação às paisagens.

\section{MATERIAL E MÉTODOS}

\section{Caracterização da área de estudo}

O Parque Natural Municipal Tanguá, cujo nome deriva da língua indígena local e significa "Baía das Conchas", possui área total igual a 235.000,00m² (CURITIBA, 2002). Está localizado na região norte da cidade de Curitiba, Estado do Paraná, nas coordenadas geográficas $25^{\circ 2}$ '39”S e 49¹7’20”W, nos bairros Pilarzinho e Taboão (Figura 01).

Segundo a classificação de Köppen, o clima da região é temperado - Cfb caracterizado por temperatura média no mês mais frio abaixo de $18^{\circ} \mathrm{C}$ (mesotérmico), com

\footnotetext{
${ }^{4}$ KLIASS, R. G. Parques urbanos de São Paulo e sua evolução na cidade. São Paulo: Pini, 1993. 
verões frescos, temperatura média no mês mais quente abaixo de $22^{\circ} \mathrm{C}$ e sem estação seca definida (IAPAR, 1994).

Originalmente a área era coberta pela Floresta Ombrófila Mista Montana (Floresta com Araucária), que hoje se encontra no estágio inicial da sucessão secundária. As principais espécies florestais observadas no local são: Mimosa scabrella (bracatinga), Ocotea puberula (canela-guaica), Allophyllus edulis (vacum), Schinus terebinthifolius (aroeira), Myrsine ferruginea (capororoca), Sapium glandulatum (leiteiro), Lithraea brasiliensis (bugreiro) (CURITIBA, 2002).

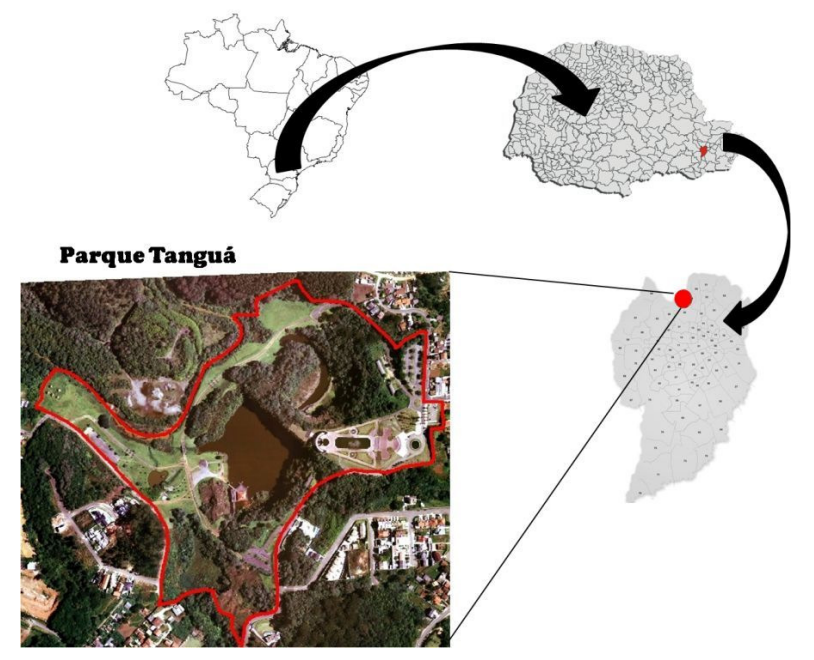

FIGURA 01 - LOCALIZAÇÃO DA ÁREA DE ESTUDO

Esse parque foi criado em 1996 em local inicialmente destinado para abrigar uma usina de reciclagem de caliça e lixo industrial (CURITIBA, 2008), em virtude de ser o resultado de um conjunto de pedreiras desativadas (CURITIBA, 2002). A sua criação teve como objetivos principais: a preservação ambiental da área de influência do rio Barigüi; a proposição de usos não conflitantes com o fundo de vale e a contenção de invasões em áreas de risco de enchentes (CURITIBA, 2002).

Biondi e Mórmul (2004) pesquisando a preferência dos usuários dos parques urbanos de Curitiba-PR constataram que a maioria dos visitantes do Parque Tanguá freqüenta o local esporadicamente, devido ao fato de ser, em grande parte, turista ou talvez em função da localização do parque. Os resultados quanto ao seu uso foram: $75,4 \%$ dos usuários visitam o parque a passeio, $44,9 \%$ estão acompanhados com suas famílias e as visitas são realizadas com duração média de 1 hora.

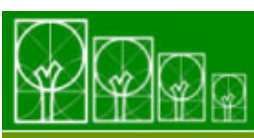

$\mathbf{S} \cdot \mathbf{B} \cdot \mathbf{A} \cdot \mathbf{U}$ Soc. Bras. de Arborização Urbana 


\section{Análise da qualidade visual da paisagem}

A análise da qualidade visual da paisagem do parque e do seu entorno foi realizada através do método direto utilizando-se substitutos da paisagem (fotografias) e consulta (entrevista) com os visitantes da área para analisar suas preferências.

Analise e classificação técnica das paisagens

Foram selecionados dezoito locais no parque, os quais representavam ambientes de maior visitação, tais como: mirantes, pontes, acessos e churrasqueiras; e três pontos fora do parque com observação para a área interna do mesmo. Nesses locais foram tomadas fotografias nos sentidos norte, sul, leste e oeste, sendo que em alguns pontos optou-se pela tomada das fotografias nos sentidos paralelo e perpendicular ao mirante principal, para maior representatividade paisagística.

Do total de fotografias obtidas, 43 foram sorteadas aleatoriamente para representar a paisagem observada no parque para fins de valoração da qualidade visual da paisagem.

Os substitutos da paisagem (fotografias) do parque foram valorados em função da presença dos componentes naturais e antrópicos da paisagem. Foram considerados componentes naturais da paisagem: vegetação, céu, rocha e água e componentes antrópicos: urbanização e elementos arquitetônicos do parque.

A presença de componentes naturais recebeu valoração positiva, representando uma melhor qualidade visual, assim como o componente arquitetônico do parque que visa embelezar a área anteriormente degradada. Em contra partida, a presença de urbanização representou uma diminuição dos componentes naturais na paisagem, recebendo valoração negativa (Tabela 01).

Os componentes vegetação e água possuem dois elementos cada e o componente arquitetônico possui 09 elementos, conforme Tabela 01.

\section{TABELA 01 - VALORAÇÃO DOS COMPONENTES DA PAISAGEM DO PARQUE}

\begin{tabular}{lclc}
\multicolumn{1}{c}{ Componente Natural } & Peso & Componente Antrópico & Peso \\
\hline Céu & 1,0 & Urbanização & $-3,0$ \\
Rocha & 2,0 & Arquitetônico: & 3,05 \\
Vegetação: & & a) Acesso & 3,05 \\
a) Herbácea & 3,1 & b) Portal & 3,05 \\
b) Arbórea & 3,2 & c) Churrasqueiras & 3,1 \\
Água: & & d) Mirante de madeira & 3,1 \\
a) Córrego & 3,1 & e) Pontes & 3,1 \\
b) Lago & 3,2 & f) Lanchonete & 3,15 \\
& & g) Queda d'água & 3,2 \\
& & h) Mirante de alvenaria & 3,2 \\
\hline
\end{tabular}


Entre os componentes naturais considerou-se que o elemento céu teria menor peso $(1,0)$ de forma a não afetar significativamente a valoração se estivesse presente em grande quantidade, deixando os elementos terrestres em menor valoração. Isto foi feito porque se pretendia, também, proceder à avaliação das perturbações do entorno do parque (urbanização). Dentre os demais componentes naturais da paisagem, a água e a vegetação foram as que mais se destacaram, ficando a rocha em segundo lugar (peso 2,0). 0 elemento água foi subdividido em lago (peso 3,2) e córrego (peso 3,1), sendo o primeiro de maior destaque, enquanto que o elemento vegetação foi subdividido em herbáceo (peso 3,1 ) e arbóreo (peso 3,2), sendo o segundo mais atrativo (Tabela 01), por simbolizar um ambiente com menor freqüência de intervenções. Os elementos arquitetônicos observados no parque foram: acessos, portal, churrasqueiras, mirante de madeira, pontes, lanchonete, queda d'água, mirante de alvenaria e espelho d'água. Cada um deles recebeu um peso diferenciado considerando sua importância arquitetônica e turística, conforme a Tabela 01.

A quantificação dos componentes e elementos da paisagem nas fotografias foi realizada da seguinte forma: imprimiu-se cada quatro fotografias (com $9 \times 13 \mathrm{~cm} \mathrm{cada}$ ) em uma folha de papel A4 e sobre esta foi colocado um papel transparência reticulado $(9 \times 13$ $\mathrm{mm}$, totalizando 90 quadrículas por fotografia) de acordo com a disposição das fotos no papel; contou-se, então, o número de quadrículas existentes sobre determinado elemento ou componente, sendo que, quando mais de um deles estava presente em uma quadrícula considerava-se apenas aquele predominante.

A qualidade visual da paisagem de cada fotografia foi obtida a partir da somatória dos valores obtidos na multiplicação da quantidade dos elementos presentes pelo peso de cada elemento, conforme a Tabela 01 . As classes de qualidade visual da paisagem foram definidas como baixa, média e alta.

As paisagens foram ainda caracterizadas quanto à heterogeneidade (número de elementos da paisagem), posição de observação (indica se a fotografia foi obtida de uma posição superior, inferior ou em nível em relação ao primeiro plano de visão) e intervisibilidade (aponta o número de planos de visão observados na fotografia).

Análise da preferência dos visitantes

A seleção das paisagens (fotografias) mostradas ao público, em dois finais de semana, foi baseada na classificação da qualidade visual da paisagem (QVP) das 43

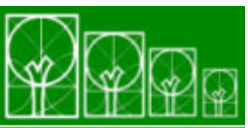

$\mathbf{S} \cdot \mathbf{B} \cdot \mathbf{A} \cdot \mathbf{U}$ Soc. Bras. de Arborização Urbana 
paisagens valoradas. As fotografias selecionadas foram aquelas correspondentes aos limites extremos de cada classe, totalizando seis fotos. Optou-se por um número pequeno de fotos (6) para facilitar as entrevistas com os visitantes do parque.

Aos visitantes foram mostradas as seis fotografias, para que escolhessem a mais agradável visualmente (com melhor qualidade visual), colocando-as em ordem de preferência e indicando, para a primeira e a última colocada, os motivos da escolha. Obtevese ainda informação sobre idade, gênero, procedência, grau de instrução de cada visitante e se possuía formação relacionada com meio ambiente.

Todos os dados foram processados e analisados estatisticamente por meio da análise multivariada, utilizando o programa computacional Statigraphics plus 5.1, realizando a correlação de dados (correlação de Spearman) e a análise de agrupamento (Cluster analysis), bem como, análise não-paramétrica para avaliação da aderência dos dados.

\section{RESULTADOS E DISCUSSÃO}

\section{Análise técnica das paisagens}

Foram selecionadas 43 fotografias para a valoração da paisagem (Figura 02). Dessas, 13 fotografias tiveram a qualidade visual da paisagem classificada como Alta (A), 14 como Média (M) e 16 como Baixa (B), conforme tabelas 02 e 03. As proporções de cada classe constantes na Tabela 02 apresentaram pouca diferença: 37,21\% na classe B, $32,56 \%$ na classe $\mathrm{M} \mathrm{e} 30,23 \%$ na classe $\mathrm{A}$. A maior concentração de fotografias na classe $\mathrm{B}$ deve-se ao agrupamento dos dados (Cluster analysis), que levou em consideração a maior correlação dos elementos vegetação arbórea, céu e urbanização com a qualidade visual da paisagem (Tabela 04). 

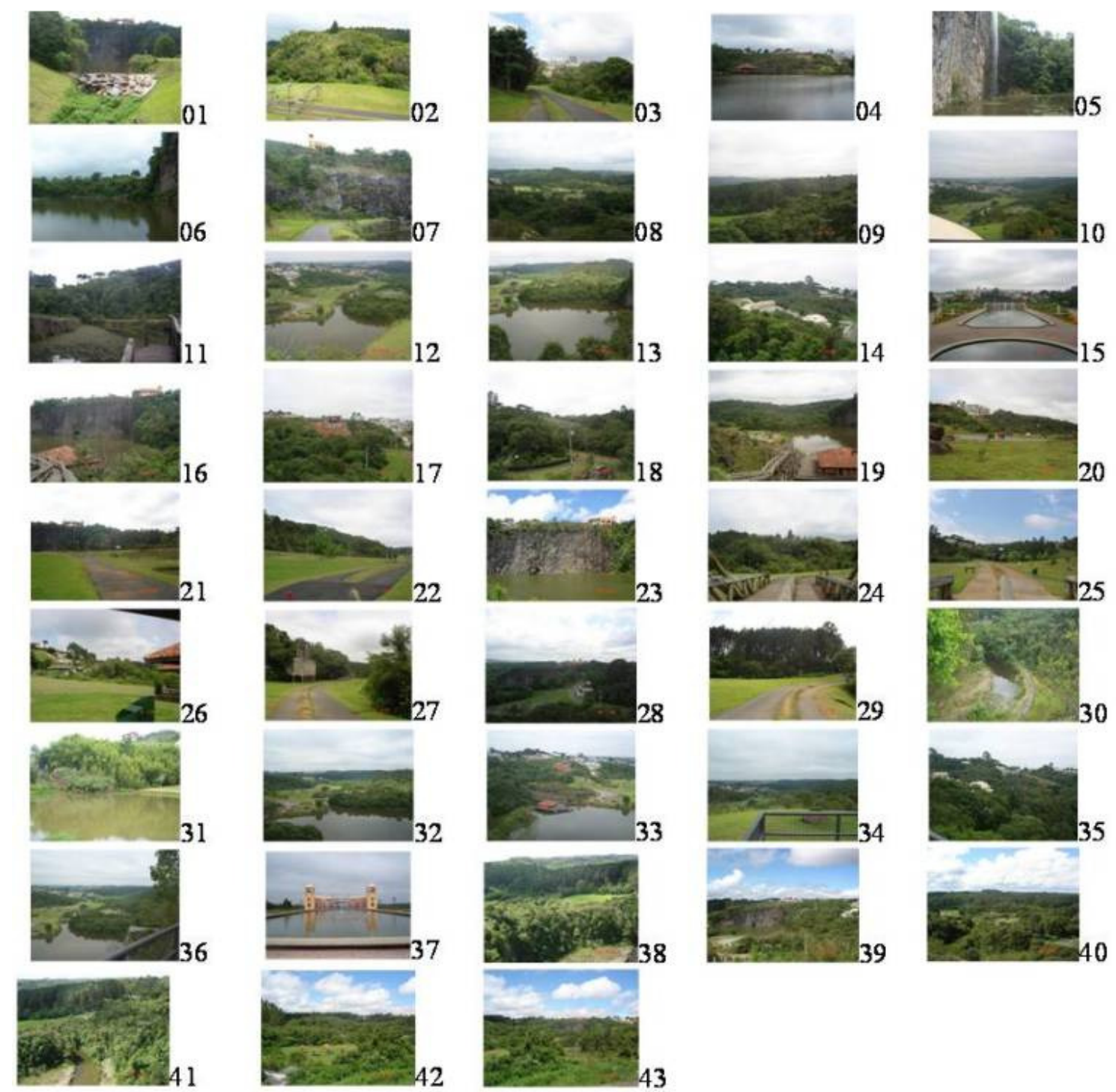

FIGURA 02 - PAISAGENS SELECIONADAS PARA AVALIAÇÃO TÉCNICA

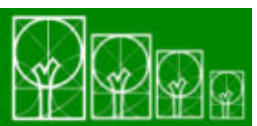


TABELA 02 - QUANTIDADE DOS ELEMENTOS DA PAISAGEM, HETEROGENEIDADE, POSIÇÃO DE OBSERVAÇÃO E QUALIDADE VISUAL DAS PAISAGENS VALORADAS.

\begin{tabular}{|c|c|c|c|c|c|c|c|c|c|c|c|c|c|c|c|c|c|c|c|c|c|}
\hline \multirow{3}{*}{ Foto } & \multicolumn{2}{|c|}{ Vegetação } & \multirow{3}{*}{ C } & \multirow{3}{*}{$\mathbf{R}$} & \multicolumn{3}{|c|}{ Água } & \multirow{2}{*}{\multicolumn{9}{|c|}{$\begin{array}{c}\text { Componente Antrópico } \\
\text { Elementos arquitetônicos do } \\
\text { parque }\end{array}$}} & \multirow{3}{*}{ HET } & \multirow{3}{*}{ PO } & \multirow{3}{*}{ INT } & \multirow{2}{*}{\multicolumn{2}{|c|}{ QVP }} \\
\hline & \multirow[t]{2}{*}{$\mathbf{H}$} & \multirow{2}{*}{ A } & & & \multirow[t]{2}{*}{$\mathbf{L}$} & \multirow[t]{2}{*}{ C } & \multirow[t]{2}{*}{$\mathbf{U}$} & & & & & & & & & & & & & & \\
\hline & & & & & & & & 1 & 2 & 3 & 4 & 5 & 6 & 7 & 8 & 9 & & & & valor & classe \\
\hline 1 & 34 & 27 & 5 & 9 & 4 & 0 & 9 & 0 & 0 & 2 & 0 & 0 & 0 & 0 & 0 & 0 & 6 & 2 & 2 & 207 & B \\
\hline 2 & 29 & 49 & 12 & 0 & 0 & 0 & 0 & 0 & 0 & 0 & 0 & 0 & 0 & 0 & 0 & 0 & 3 & 3 & 2 & 258,7 & $A$ \\
\hline 3 & 18 & 30 & 21 & 0 & 0 & 0 & 3 & 18 & 0 & 0 & 0 & 0 & 0 & 0 & 0 & 0 & 5 & 2 & 2 & 218,7 & $B$ \\
\hline 4 & 4 & 5 & 29 & 2 & 40 & 0 & 6 & 0 & 0 & 0 & 0 & 0 & 0 & 0 & 4 & 0 & 7 & 2 & 2 & 183,8 & $B$ \\
\hline 5 & 0 & 28 & 7 & 33 & 15 & 0 & 0 & 0 & 0 & 0 & 0 & 0 & 7 & 0 & 0 & 0 & 5 & 2 & 1 & 232,65 & $A$ \\
\hline 6 & 0 & 16 & 33 & 8 & 33 & 0 & 0 & 0 & 0 & 0 & 0 & 0 & 0 & 0 & 0 & 0 & 4 & 2 & 2 & 205,8 & $\mathrm{M}$ \\
\hline 7 & 15 & 23 & 11 & 33 & 3 & 0 & 0 & 2 & 0 & 1 & 2 & 0 & 0 & 0 & 0 & 0 & 8 & 2 & 2 & 222,2 & $A$ \\
\hline 8 & 9 & 50 & 30 & 0 & 0 & 0 & 1 & 0 & 0 & 0 & 0 & 0 & 0 & 0 & 0 & 0 & 4 & 3 & 3 & 214,9 & $\mathrm{M}$ \\
\hline 9 & 2 & 49 & 39 & 0 & 0 & 0 & 0 & 0 & 0 & 0 & 0 & 0 & 0 & 0 & 0 & 0 & 3 & 2 & 3 & 202 & $\mathrm{M}$ \\
\hline 10 & 8 & 28 & 40 & 1 & 0 & 1 & 7 & 0 & 0 & 5 & 0 & 0 & 0 & 0 & 0 & 0 & 7 & 2 & 3 & 154,5 & $B$ \\
\hline 11 & 3 & 35 & 18 & 7 & 19 & 0 & 0 & 0 & 0 & 0 & 8 & 0 & 0 & 0 & 0 & 0 & 6 & 3 & 1 & 238,9 & $A$ \\
\hline 12 & 19 & 20 & 10 & 5 & 24 & 1 & 10 & 1 & 0 & 0 & 0 & 0 & 0 & 0 & 0 & 0 & 8 & 2 & 3 & 195,85 & B \\
\hline 13 & 4 & 41 & 8 & 2 & 32 & 0 & 2 & 1 & 0 & 0 & 0 & 0 & 0 & 0 & 0 & 0 & 7 & 3 & 3 & 255,05 & $A$ \\
\hline 14 & 0 & 57 & 24 & 0 & 0 & 0 & 9 & 0 & 0 & 0 & 0 & 0 & 0 & 0 & 0 & 0 & 3 & 3 & 2 & 179,4 & $B$ \\
\hline 15 & 0 & 5 & 30 & 0 & 0 & 0 & 7 & 0 & 0 & 0 & 0 & 0 & 0 & 48 & 0 & 0 & 4 & 3 & 2 & 178,6 & $B$ \\
\hline 16 & 0 & 27 & 18 & 20 & 11 & 0 & 0 & 0 & 0 & 2 & 5 & 0 & 0 & 0 & 7 & 0 & 7 & 3 & 2 & 223,2 & $A$ \\
\hline 17 & 5 & 30 & 37 & 0 & 0 & 0 & 18 & 0 & 0 & 0 & 0 & 0 & 0 & 0 & 0 & 0 & 4 & 3 & 1 & 94,5 & B \\
\hline 18 & 8 & 40 & 34 & 1 & 0 & 0 & 0 & 7 & 0 & 0 & 0 & 0 & 0 & 0 & 0 & 0 & 5 & 3 & 1 & 210,15 & $\mathrm{M}$ \\
\hline 19 & 6 & 27 & 24 & 10 & 8 & 0 & 0 & 0 & 0 & 0 & 7 & 0 & 0 & 0 & 8 & 0 & 7 & 3 & 2 & 221,1 & A \\
\hline 20 & 34 & 8 & 32 & 5 & 0 & 0 & 4 & 6 & 0 & 0 & 1 & 0 & 0 & 0 & 0 & 0 & 7 & 2 & 2 & 182,4 & $B$ \\
\hline 21 & 24 & 13 & 29 & 8 & 0 & 0 & 0 & 15 & 0 & 1 & 0 & 0 & 0 & 0 & 0 & 0 & 6 & 2 & 2 & 209,95 & $\mathrm{M}$ \\
\hline 22 & 20 & 18 & 35 & 0 & 0 & 0 & 0 & 13 & 0 & 0 & 0 & 0 & 0 & 0 & 0 & 4 & 5 & 2 & 1 & 206,45 & $M$ \\
\hline 23 & 0 & 12 & 17 & 31 & 27 & 0 & 0 & 0 & 0 & 3 & 0 & 0 & 0 & 0 & 0 & 0 & 5 & 2 & 1 & 213,4 & $A$ \\
\hline 24 & 0 & 29 & 37 & 0 & 0 & 0 & 0 & 2 & 0 & 0 & 22 & 0 & 0 & 0 & 0 & 0 & 4 & 2 & 1 & 204,1 & $M$ \\
\hline 25 & 13 & 17 & 40 & 0 & 0 & 0 & 2 & 10 & 0 & 0 & 8 & 0 & 0 & 0 & 0 & 0 & 6 & 2 & 2 & 184 & $\mathrm{M}$ \\
\hline 26 & 29 & 6 & 33 & 0 & 0 & 0 & 10 & 0 & 0 & 0 & 0 & 12 & 0 & 0 & 0 & 0 & 5 & 2 & 1 & 148,7 & B \\
\hline 27 & 15 & 34 & 25 & 0 & 0 & 0 & 8 & 8 & 0 & 0 & 0 & 0 & 0 & 0 & 0 & 0 & 5 & 2 & 1 & 180,7 & $B$ \\
\hline 28 & 1 & 37 & 40 & 4 & 0 & 0 & 1 & 6 & 0 & 1 & 0 & 0 & 0 & 0 & 0 & 0 & 7 & 3 & 3 & 188 & M \\
\hline 29 & 17 & 50 & 14 & 0 & 0 & 0 & 0 & 9 & 0 & 0 & 0 & 0 & 0 & 0 & 0 & 0 & 4 & 1 & 1 & 254,15 & A \\
\hline 30 & 6 & 69 & 0 & 4 & 9 & 0 & 0 & 2 & 0 & 0 & 0 & 0 & 0 & 0 & 0 & 0 & 5 & 3 & 1 & 282,3 & $A$ \\
\hline 31 & 44 & 0 & 4 & 0 & 40 & 0 & 2 & 0 & 0 & 0 & 0 & 0 & 0 & 0 & 0 & 0 & 4 & 2 & 1 & 262,4 & $A$ \\
\hline 32 & 4 & 31 & 30 & 1 & 17 & 1 & 5 & 1 & 0 & 0 & 0 & 0 & 0 & 0 & 0 & 0 & 8 & 3 & 3 & 189,15 & $B$ \\
\hline 33 & 14 & 18 & 19 & 5 & 16 & 0 & 12 & 1 & 0 & 0 & 2 & 0 & 0 & 0 & 3 & 0 & 9 & 3 & 3 & 163,75 & B \\
\hline 34 & 24 & 21 & 40 & 0 & 0 & 0 & 5 & 0 & 0 & 0 & 0 & 0 & 0 & 0 & 0 & 0 & 4 & 2 & 3 & 166,6 & $B$ \\
\hline 35 & 0 & 56 & 25 & 0 & 0 & 0 & 9 & 0 & 0 & 0 & 0 & 0 & 0 & 0 & 0 & 0 & 3 & 3 & 1 & 177,2 & B \\
\hline 36 & 5 & 38 & 24 & 0 & 13 & 1 & 4 & 2 & 0 & 0 & 0 & 0 & 3 & 0 & 0 & 0 & 8 & 3 & 3 & 209,35 & B \\
\hline 37 & 0 & 4 & 36 & 0 & 0 & 0 & 0 & 0 & 0 & 6 & 0 & 0 & 0 & 44 & 0 & 0 & 4 & 2 & 1 & 208,8 & $\mathrm{M}$ \\
\hline 38 & 5 & 78 & 5 & 2 & 0 & 0 & 0 & 0 & 0 & 0 & 0 & 0 & 0 & 0 & 0 & 0 & 4 & 3 & 3 & 274,1 & A \\
\hline 39 & 10 & 26 & 40 & 4 & 5 & 0 & 2 & 2 & 0 & 1 & 0 & 0 & 0 & 0 & 0 & 0 & 8 & 3 & 2 & 181,5 & $\mathrm{M}$ \\
\hline 40 & 5 & 50 & 35 & 0 & 0 & 0 & 0 & 0 & 0 & 0 & 0 & 0 & 0 & 0 & 0 & 0 & 3 & 3 & 3 & 210,5 & $\mathrm{M}$ \\
\hline 41 & 4 & 73 & 5 & 3 & 3 & 0 & 0 & 2 & 0 & 0 & 0 & 0 & 0 & 0 & 0 & 0 & 6 & 3 & 3 & 272,7 & A \\
\hline 42 & 6 & 48 & 29 & 0 & 0 & 0 & 3 & 0 & 0 & 0 & 0 & 4 & 0 & 0 & 0 & 0 & 5 & 3 & 2 & 204,4 & $\mathrm{M}$ \\
\hline 43 & 20 & 27 & 38 & 2 & 0 & 0 & 1 & 0 & 0 & 1 & 0 & 1 & 0 & 0 & 0 & 0 & 7 & 3 & 2 & 193,65 & $\mathrm{M}$ \\
\hline
\end{tabular}

Nota: Vegetação: H - herbácea, A- arbórea; C - céu; R - rocha; Água: L - lago, C - córrego; Elemento antrópico: U urbanização; 1 - acesso, 2 - mirante de madeira, 3 - mirante de alvenaria, 4 - ponte, 5 - churrasqueira, 6 - queda d'água, 7 espelho d'água, 8 - lanchonete, 9 - portal; HET - Heterogeneidade; PO - posição de observação: 1 - inferior, 2 - em nível, 3 superior; INT - intervisibilidade, 1 - um plano, 2 - dois planos, 3 - três planos; QVP - qualidade visual da paisagem: V - valor, $\mathrm{B}$ - baixa, $\mathrm{M}$ - média, $\mathrm{A}$ - alta. 
TABELA 03 - ESTATÍSTICA DESCRITIVA DAS PAISAGENS VALORADAS

\begin{tabular}{l|c|c|c|c}
\hline & Total & Classe B & Classe M & Classe A \\
\hline Número fotos & 43 & 16 & 14 & 13 \\
Relativo (\%) & 100 & 37,21 & 32,56 & 30,23 \\
Média QVP & 206,17 & 176,89 & 201,73 & 246,99 \\
Desvio Padrão & 36,58 & 10,63 & 28,73 & 23,06 \\
\hline
\end{tabular}

TABELA 04 - MATRIZ DE CORRELAÇÃO ENTRE OS ELEMENTOS NATURAIS E ANTRÓPICOS, HETEROGENEIDADE, POSIÇÃO DE OBSERVAÇÃO, INTERVISIBILIDADE E QUALIDADE VISUAL DA PAISAGEM DAS FOTOGRAFIAS.

\begin{tabular}{|c|c|c|c|c|c|c|c|c|c|c|c|c|c|c|c|c|c|c|}
\hline \multicolumn{2}{|c|}{ Vegetação } & \multirow{3}{*}{ C } & \multirow{3}{*}{$\mathbf{R}$} & \multicolumn{3}{|c|}{ Água } & \multicolumn{8}{|c|}{ Elemento Antrópico } & \multirow{3}{*}{ HET } & \multirow{3}{*}{ PO } & \multirow{3}{*}{ INT } & \multirow{3}{*}{ QVP } \\
\hline \multirow{2}{*}{$\mathbf{H}$} & \multirow{2}{*}{ A } & & & \multirow{2}{*}{$\mathbf{L}$} & \multirow{2}{*}{ C } & \multirow{2}{*}{$\mathbf{U}$} & \multicolumn{8}{|c|}{ Arquitetura } & & & & \\
\hline & & & & & & & 1 & 2 & 3 & 4 & 5 & 6 & 7 & 8 & & & & \\
\hline
\end{tabular}

\begin{tabular}{|c|c|c|c|c|c|c|c|c|c|c|c|c|c|c|c|c|c|c|}
\hline $\mathrm{H}$ & 1 & & & & & & & & & & & & & & & & & \\
\hline A & $-0,34$ & 1 & & & & & & & & & & & & & & & & \\
\hline$C$ & $-0,16$ & $-0,32$ & 1 & & & & & & & & & & & & & & & \\
\hline $\mathrm{R}$ & $-0,14$ & $-0,19$ & $-0,37$ & 1 & & & & & & & & & & & & & & \\
\hline $\mathrm{L}$ & $-0,03$ & $-0,33$ & $-0,38$ & 0,26 & 1 & & & & & & & & & & & & & \\
\hline C & $-0,05$ & $-0,04$ & 0,03 & $-0,11$ & 0,17 & 1 & & & & & & & & & & & & \\
\hline$U$ & 0,14 & $-0,18$ & 0,11 & $-0,26$ & $-0,02$ & 0,25 & 1 & & & & & & & & & & & \\
\hline 1 & 0,27 & $-0,10$ & 0,13 & $-0,14$ & $-0,29$ & $-0,11$ & $-0,18$ & 1 & & & & & & & & & & \\
\hline 2 & $-0,12$ & $-0,28$ & 0,15 & 0,21 & $-0,08$ & 0,18 & $-0,08$ & $-0,13$ & 1 & & & & & & & & & \\
\hline 3 & $-0,18$ & $-0,08$ & 0,14 & 0,04 & $-0,06$ & $-0,11$ & $-0,19$ & 0,00 & $-0,08$ & 1 & & & & & & & & \\
\hline 4 & 0,23 & $-0,16$ & 0,13 & $-0,11$ & $-0,13$ & $-0,07$ & 0,22 & $-0,12$ & $-0,08$ & $-0,07$ & 1 & & & & & & & \\
\hline 5 & $-0,17$ & 0,00 & $-0,21$ & 0,44 & 0,12 & 0,15 & $-0,10$ & $-0,09$ & $-0,09$ & $-0,07$ & $-0,04$ & 1 & & & & & & \\
\hline 6 & $-0,22$ & $-0,32$ & 0,15 & $-0,12$ & $-0,14$ & $-0,07$ & 0,02 & $-0,13$ & 0,40 & $-0,07$ & $-0,05$ & $-0,05$ & 1 & & & & & \\
\hline 7 & $-0,16$ & $-0,15$ & $-0,06$ & 0,22 & 0,22 & $-0,10$ & $-0,04$ & $-0,16$ & 0,02 & 0,24 & $-0,06$ & $-0,06$ & $-0,07$ & 1 & & & & \\
\hline 8 & 0,13 & $-0,11$ & 0,13 & $-0,08$ & $-0,10$ & $-0,05$ & $-0,12$ & 0,37 & $-0,06$ & $-0,05$ & $-0,03$ & $-0,03$ & $-0,03$ & $-0,05$ & 1 & & & \\
\hline HET & 0,07 & $-0,29$ & $-0,06$ & 0,27 & 0,28 & 0,44 & 0,10 & 0,06 & 0,11 & 0,03 & $-0,04$ & 0,05 & $-0,19$ & 0,32 & $-0,04$ & 1 & & \\
\hline PO & $-0,38$ & 0,46 & $-0,03$ & $-0,16$ & $-0,08$ & 0,01 & 0,06 & $-0,36$ & $-0,21$ & $-0,05$ & $-0,07$ & $-0,07$ & 0,01 & 0,18 & $-0,14$ & 0,11 & 1 & \\
\hline INT & $-0,09$ & 0,24 & 0,07 & $-0,17$ & 0,01 & 0,41 & 0,02 & $-0,16$ & $-0,06$ & $-0,21$ & $-0,18$ & $-0,10$ & $-0,13$ & 0,06 & $-0,19$ & 0,34 & 0,30 & 1 \\
\hline QVP & 0,03 & 0,44 & $-0,71$ & 0,18 & 0,22 & $-0,17$ & $-0,73$ & 0,05 & $-0,11$ & 0,03 & $-0,24$ & 0,11 & $-0,08$ & 0,01 & 0,00 & $-0,11$ & 0,04 & $-0,01$ \\
\hline
\end{tabular}

Nota: Vegetação: H - herbácea, A - arbórea; C - céu; R - rocha; Água: L - lago, C - córrego; Elemento antrópico: U urbanização; 1 - acesso, 2 - mirante de alvenaria, 3 - ponte, 4 - churrasqueira, 5 - queda d'água, 6 - espelho d'água, 7 lanchonete, 8 - portal; HET - Heterogeneidade; PO - posição de observação; INT - intervisibilidade; QVP - qualidade visual da paisagem. Os valores em negrito indicam correlação entre os elementos da paisagem.

Houve diferença significativa ao nível de $1 \%$ de probabilidade entre os resultados da qualidade visual da paisagem observados para cada paisagem, bem como entre as classes de paisagem formadas (Tabela 05). Tal resultado foi obtido mediante aplicação do teste qui-quadrado. Constatou-se então que a metodologia aplicada para valoração possibilitou diferenciar as paisagens avaliadas, bem como, o agrupamento em classes possibilitou a distinção de grupos de qualidade visual da paisagem. Porém, Ceotma (1984) afirmou que uma das grandes dificuldades para a aplicação de métodos de avaliação da qualidade visual da paisagem é a seleção de paisagens distintas. 
TABELA 05 - SIGNIFICÂNCIA DA DIFERENÇA ENTRE PAISAGENS E CLASSE DE PAISAGENS

\begin{tabular}{c|c|c|c}
\hline & G.L. & $\chi^{2}$ tab & $\chi^{2}$ calc \\
\hline Todas as paisagens & 42 & 66,21 & $272,54^{* *}$ \\
\hline Classes de paisagem & 2 & 5,99 & $12,12^{* *}$ \\
\hline
\end{tabular}

** Significativo ao nível de $1 \%$ de probabilidade

A Figura 03 mostra os agrupamentos das paisagens em cada classe de qualidade visual. Nota-se que as classes média e baixa estão mais próximas, indicando que as paisagens dessas classes são mais parecidas, enquanto as paisagens da classe alta são mais distintas das anteriores.

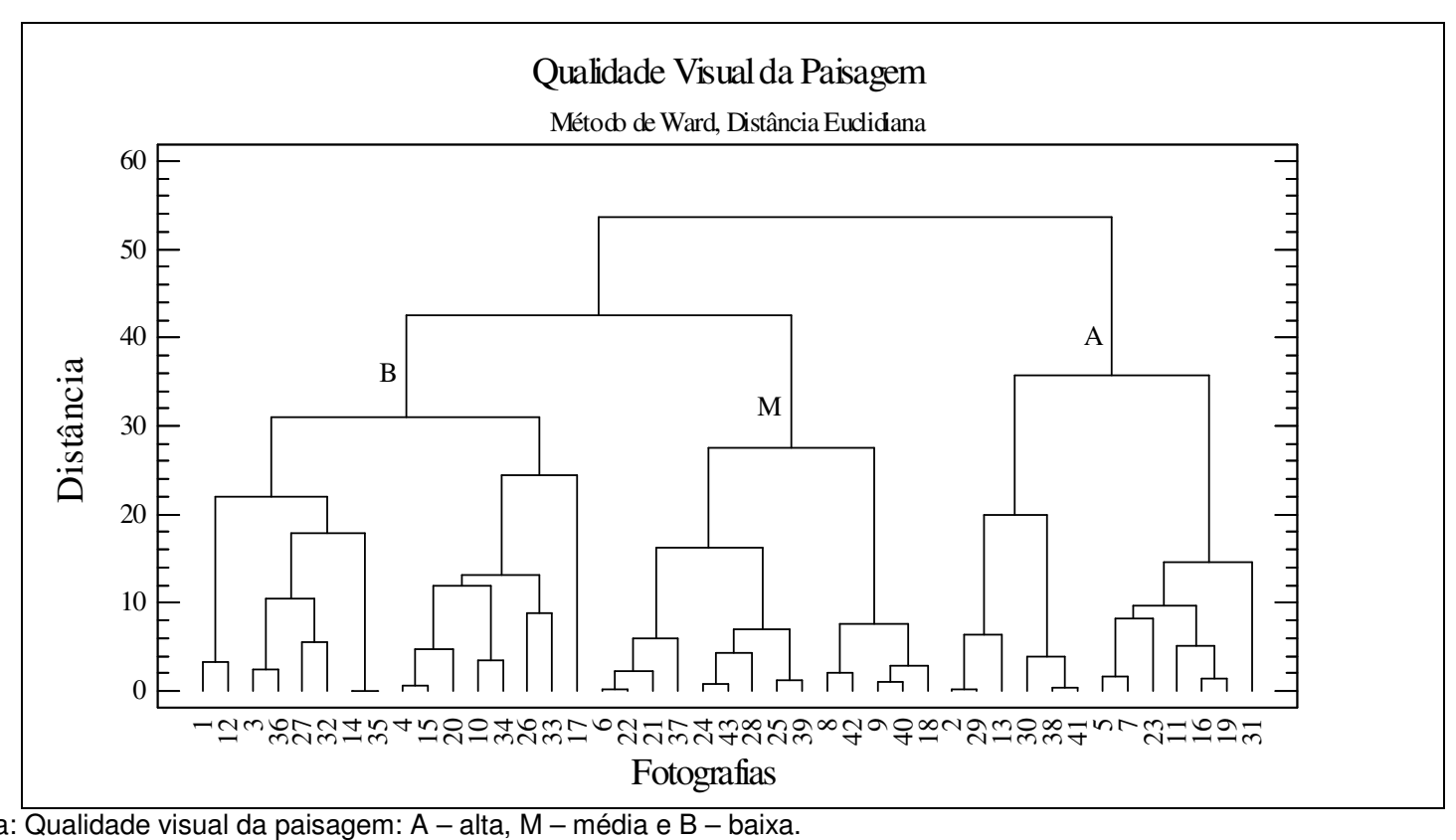

Nota: Qualidade visual da paisagem: A - alta, M - média e B - baixa.

FIGURA 03 - ANÁLISE DE AGRUPAMENTO (CLUSTER ANALYSIS) DAS PAISAGENS DO PARQUE TANGUÁ E DE SEU ENTORNO.

De maneira geral as paisagens da classe alta apresentaram pouca urbanização, pouco elemento céu e muita vegetação em relação às outras classes. Estas paisagens foram obtidas no interior do parque, as quais mostram ambientes internos e do entorno norte. As paisagens da classe baixa apresentaram urbanização e céu em maior quantidade que a classe alta, mostrando o entorno sul e oeste do parque. As paisagens de classe média apresentaram pouca vegetação e muito céu em relação às outras classes. As paisagens observadas de fora do parque, ou seja, aquelas que apresentaram uma visão panorâmica do parque, também se enquadraram nesta classe.

Nota-se, na tabela 04, que a qualidade visual da paisagem teve uma alta correlação negativa com os componentes céu $(-0,71)$ e urbanização $(-0,73)$, os quais constituíram fatores de depreciação do valor da qualidade da paisagem em proporções distintas, bem 
como, constatou-se uma moderada correlação positiva com o elemento vegetação arbórea $(0,44)$.

Entre os elementos naturais, quanto maior a presença de céu, menor a presença de vegetação arbórea, rocha e lago. A maior ou menor presença de céu foi conseqüência da posição e da direção em que as fotografias foram obtidas. A maior proporção de céu nas fotos também afetou, negativamente, a heterogeneidade dessas (Tabela 04).

A maior proporção de vegetação arbórea foi afetada positivamente pela localização do ponto de observação da paisagem, afetando positivamente, por conseqüência, a intervisibilidade e a qualidade visual da paisagem e negativamente a heterogeneidade, pois conforme o plano de observação tinha-se uma visão monótona da paisagem composta quase unicamente por espécies arbóreas (Tabela 04).

Em relação à posição de observação, nas paisagens em nível predominaram os acessos e a vegetação herbácea, enquanto na posição superior predominou a vegetação arbórea. Isso porque nas porções de maior altitude do parque consegue-se ter mais planos de visão e conseqüente visualização de mais elementos nas paisagens, principalmente da vegetação arbórea do parque e do seu entorno.

Percebe-se através da Figura 04 que o elemento vegetação arbórea teve maior presença nas paisagens valoradas, seguido dos elementos céu e vegetação herbácea. Esses três elementos responderam juntos por $81,27 \%$ do total constante nas paisagens avaliadas. Salienta-se que a vegetação é o componente que mais contribui para a caracterização da naturalidade de um ambiente (LUCAS, 1991).

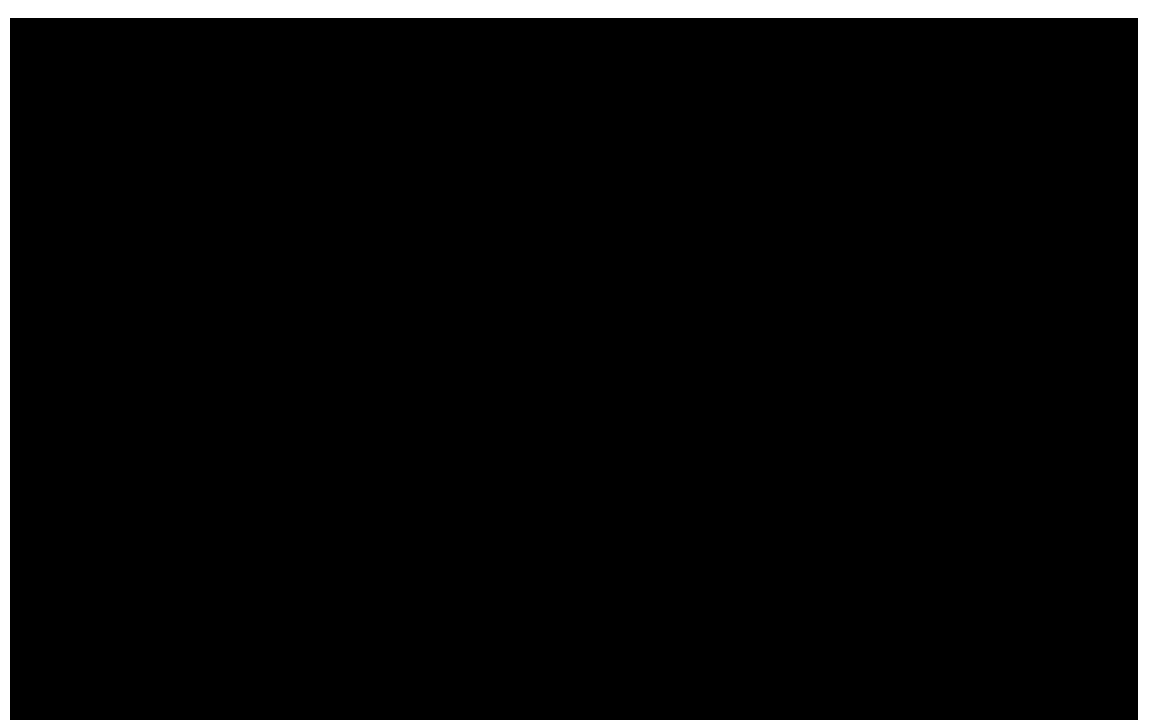

FIGURA 04 - PRINCIPAIS ELEMENTOS PRESENTES NAS PAISAGENS VALORADAS

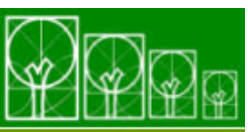

$\mathbf{S} \cdot \mathbf{B} \cdot \mathbf{A} \cdot \mathbf{U}$ Soc. Bras. de Arborização Urbana 
Devido ao sistema de valoração adotado a predominância da melhor qualidade visual para paisagens ocorreu onde havia maior proporção de vegetação arbórea, conforme valor obtido pela análise da paisagem da fotografia 38. Também, foi possível obter valores menores para as paisagens onde ocorria urbanização e conseqüente depreciação visual da paisagem natural do entorno imediato do parque. Este tipo de resultado também foi obtido pela metodologia empregada por Gonzaga et al. (2004) num estudo sobre as trilhas do Parque Passaúna em Curitiba. Por outro lado, no estudo conduzido por Bulut e Yilmaz (2008) em Kemaliye, na Turquia, a paisagem com maior valoração foi aquela onde ocorriam casas com arquiteturas tradicionais entremeadas à vegetação e montanhas locais de forma harmônica e integrada, numa escala reduzida.

\subsection{PREFERÊNCIAS DOS VISITANTES}

As paisagens utilizadas para avaliação nas entrevistas foram aquelas correspondentes às fotografias de número 03, 08, 17, 23, 38 e 39 (Figura 05). A fotografia 30 (maior qualidade visual - Tabela 02) não apresentou o elemento céu, representando, portanto, uma paisagem com plano de visão único e restrito. Considerou-se que isto poderia influenciar na ordenação desta fotografia pelos visitantes, sendo então substituída pela fotografia 38 (segunda maior qualidade visual, para a classe alta, onde ambas foram inseridas). 

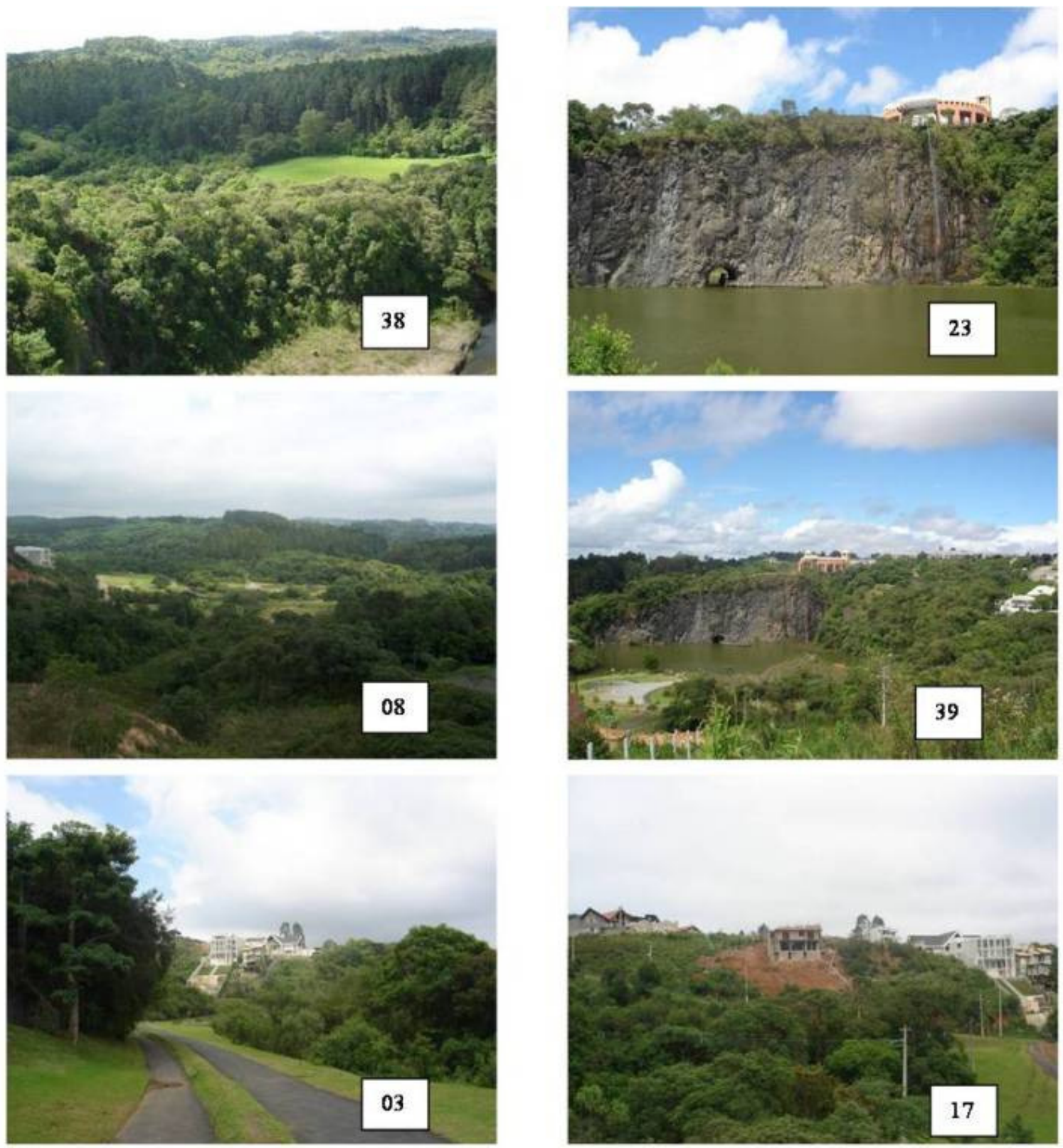

FIGURA 05 - PAISAGENS APRESENTADAS AOS VISITANTES DO PARQUE TANGUÁ PARA A ANÁLISE DA PREFERÊNCIA.

As paisagens das fotografias 38 e 23 foram classificadas como qualidade visual alta na análise técnica, não apresentando a componente urbanização. As paisagens das fotografias 08 e 39 foram classificadas como qualidade visual média na análise técnica, ambas apresentando o elemento urbanização em pequena quantidade. As paisagens das fotografias 03 e 17 foram classificadas como qualidade visual baixa na análise técnica,

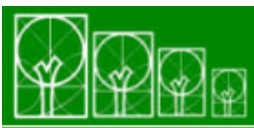

$\mathbf{S} \cdot \mathbf{B} \cdot \mathbf{A} \cdot \mathbf{U}$ Soc. Bras. de Arborização Urbana 
ambas apresentando o elemento urbanização em maior quantidade e indicando o uso do entorno imediato do parque.

Conforme resultado observado na Tabela 06, do total de 70 pessoas entrevistadas constatou-se que a maior proporção delas era do sexo feminino (57\%), da faixa etária entre 26-40 anos (34\%), com grau de instrução de nível médio (41\%), procedentes da cidade de Curitiba $(64,29 \%)$ e sem formação relacionada ao meio ambiente (97\%). O perfil dos entrevistados nesta pesquisa contrasta com os resultados encontrados por Biondi e Mórmul (2004) apenas na procedência dos usuários, que teve uma predominância de turistas provindos de outras cidades.

TABELA 06 - PERFIL DOS VISITANTES ENTREVISTADOS NO PARQUE TANGUÁ.

\begin{tabular}{|c|c|c|}
\hline \multirow{2}{*}{ Questões } & \multicolumn{2}{|c|}{ Respostas } \\
\hline & Quantidade & $\%$ \\
\hline \multicolumn{3}{|l|}{ Gênero } \\
\hline Masculino & 30 & 42,86 \\
\hline Feminino & 40 & 57,14 \\
\hline \multicolumn{3}{|l|}{ Faixa etária } \\
\hline$<12$ & 7 & 10,00 \\
\hline 12 a 18 & 11 & 15,71 \\
\hline 19 a 25 & 17 & 24,29 \\
\hline 26 a 40 & 24 & 34,29 \\
\hline 41 a 55 & 9 & 12,86 \\
\hline$>55$ & 2 & 2,86 \\
\hline \multicolumn{3}{|l|}{ Grau de instrução } \\
\hline Fundamental & 18 & 25,71 \\
\hline Médio & 29 & 41,43 \\
\hline Superior & 16 & 22,86 \\
\hline Pós-Graduação & 7 & 10,00 \\
\hline \multicolumn{3}{|l|}{ Formação relacionada com meio ambiente } \\
\hline Sim & 2 & 2,86 \\
\hline Não & 68 & 97,14 \\
\hline \multicolumn{3}{|l|}{ Procedência } \\
\hline Curitiba & 45 & 64,29 \\
\hline Região Metropolitana & 9 & 12,86 \\
\hline Paraná & 6 & 8,57 \\
\hline Outros estados & 10 & 14,29 \\
\hline
\end{tabular}

Em relação à preferência das paisagens, não se obteve nenhuma correlação entre os elementos da paisagem com o perfil dos visitantes. Porém verificou-se que todos os entrevistados indicaram a paisagem da fotografia número 17 (Tabela 07, Figura 06) como sendo a menos atrativa (sexta posição). Esta fotografia recebeu o menor valor de qualidade visual da paisagem na avaliação técnica. As demais paisagens foram ordenadas 
aleatoriamente, independentes da idade, grau de instrução, formação, gênero ou procedência dos visitantes.

A Tabela 07 apresenta a classificação das paisagens por faixa etária. Algumas paisagens empataram em número de votos, devido ao baixo número de votos que cada fotografia recebeu, provavelmente em decorrência de algum fator pessoal não detectado.

A paisagem da fotografia 17 em todas as faixas etárias foi classificada como sexto lugar (menor qualidade visual), com $100 \%$ dos votos, enquanto que a fotografia 03 foi classificada em quinto lugar, com mais de $50 \%$ dos votos, exceto na faixa $>55$, na qual houve empate (Tabela 07). Ambas as paisagens apresentaram o elemento urbanização, sendo que a maior quantidade foi observada para a paisagem 17 (Tabela 02). As demais paisagens foram classificadas aleatoriamente, com número de votos inferior a $50 \%$, sem considerar as que empataram (Tabela 07).

TABELA 07 - ORDEM DE PREFERÊNCIA DAS FOTOGRAFIAS POR FAIXA ETÁRIA DOS VISITANTES ENTREVISTADOS NO PARQUE TANGUÁ.

Ordem de preferência das fotografias

\begin{tabular}{|c|c|c|c|c|c|c|c|c|c|c|c|c|}
\hline \multirow{3}{*}{ Faixa etária } & \\
\hline & \multicolumn{2}{|c|}{$1^{a}$} & \multicolumn{2}{|c|}{$2^{\mathrm{a}}$} & \multicolumn{2}{|c|}{$3^{\mathbf{a}}$} & \multicolumn{2}{|c|}{$4^{a}$} & \multicolumn{2}{|c|}{$5^{a}$} & \multicolumn{2}{|c|}{$6^{a}$} \\
\hline & $\mathbf{P}$ & $\%$ & $\mathbf{P}$ & $\%$ & $\mathbf{P}$ & $\%$ & $\mathbf{P}$ & $\%$ & $\mathbf{P}$ & $\%$ & $\mathbf{P}$ & $\%$ \\
\hline$<12$ & * & * & 23 & 57 & * & * & 08 & 43 & 03 & 57 & 17 & 100 \\
\hline 12 a 18 & 23 & 54 & 39 & 36 & * & * & * & * & 03 & 73 & 17 & 100 \\
\hline 19 a 25 & 23 & 41 & 39 & 35 & 38 & 35 & 08 & 53 & 03 & 71 & 17 & 100 \\
\hline 26 a 40 & 23 & 38 & 23 & 42 & 38 & 46 & 08 & 54 & 03 & 86 & 17 & 100 \\
\hline 41 a 55 & * & * & * & * & * & * & 39 & 33 & 03 & 67 & 17 & 100 \\
\hline$>55$ & * & * & * & * & * & * & 39 & 100 & * & * & 17 & 100 \\
\hline
\end{tabular}

NOTA: $\mathrm{P}$ - Paisagem; ${ }^{*}$ houve empate entre as duas paisagens mais votadas.

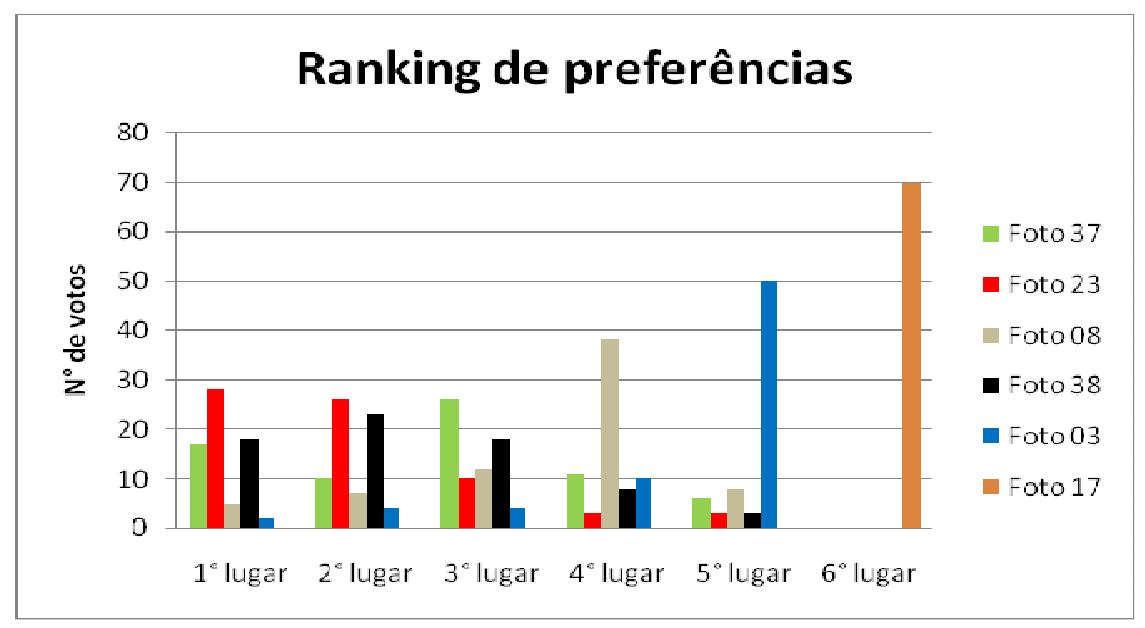

FIGURA 06 - PREFERÊNCIA DE PAISAGEM PELO PÚBLICO

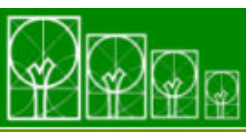


A paisagem 23 foi classificada como a mais atrativa (primeiro lugar, Figura 06), nas faixas etárias 12 a 18, 19 a 25 e 26 a 40 anos, enquanto que nas demais faixas etárias não houve uma definição (Tabela 07). Por mais que esta paisagem apresente grande quantidade dos elementos rocha e água e pequena quantidade dos elementos céu, vegetação e arquitetônico (Tabela 02), a maioria dos visitantes justificou a sua escolha pelo conjunto dos elementos (Tabela 08).

A Tabela 08 indica o motivo da classificação da primeira e da última fotografia pelos visitantes. Percebe-se que quase a metade dos visitantes (49\%) classificou a primeira fotografia observando o conjunto dos elementos da paisagem, embora $24 \%$ dos entrevistados tenham justificado sua classificação pela presença do elemento vegetação. Portanto, constata-se que há preferência das pessoas entrevistadas pela visualização de um conjunto mais harmônico de elementos na paisagem do parque (rocha, água, vegetação, arquitetura e céu), não monótono (único elemento) e sem a presença de ações antrópicas que se destaquem, tais como as construções no entorno do parque.

Bastarz (2009) analisando a preferência da paisagem do município de Morretes-PR como subsídio ao planejamento do turismo, constatou que os elementos de infra-estrutura (pontes, postes, lixeiras) e edificações (casas, sinalização turística, ruas e calçadas) contribuíram para a alta valoração da paisagem quando apareceram em estilo antigo, integrado aos componentes naturais, com sentido de acesso e liberdade de movimento às paisagens. Quanto à diversidade de elementos (naturais e antrópicos) na paisagem, foi altamente valorada a paisagem que tinha uma variedade de elementos em combinação harmoniosa e integrada ao conjunto.

TABELA 08 - MOTIVO DA CLASSIFICAÇÃO DA PRIMEIRA E DA ÚLTIMA FOTOGRAFIA PELOS VISITANTES DO PARQUE TANGUÁ.

\begin{tabular}{lcccc}
\hline \multirow{2}{*}{ Motivo da classificação } & \multicolumn{2}{c}{ Primeira paisagem } & \multicolumn{2}{c}{ Última paisagem } \\
\cline { 2 - 5 } & Quantidade & $\%$ & Quantidade & $\%$ \\
\hline Vegetação & 24 & 34,29 & 0 & 0,00 \\
Rocha & 3 & 4,29 & 0 & 0,00 \\
Água & 1 & 1,43 & 0 & 0,00 \\
Conjunto dos elementos & 34 & 48,57 & 0 & 0,00 \\
Elemento arquitetônico do parque & 5 & 7,14 & 0 & 0,00 \\
Urbanização & 0 & 0,00 & 70 & 100,00 \\
\hline
\end{tabular}

As constatações desta pesquisa e as observações acima feitas corroboram com as conclusões de Vieira et al. (2007), para as quais a preferência dos entrevistados estava associada à naturalidade da paisagem, com equilíbrio e harmonia entre os elementos constantes na cena, pois os elementos da paisagem podem não ser apreciados apenas por 
si mesmos, mas principalmente pela condição em que se apresentam: pela sua inserção no ambiente e pelo que oferecem. Também, relacionam-se com as conclusões de Bley (1990), para o qual a vegetação, apesar de importante na paisagem, não foi o elemento de maior peso na atribuição de beleza às paisagens retratadas e apresentadas em seu trabalho. No entanto, de acordo com Gonzaga et al. (2004) a água contribui muito para uma avaliação "boa" da paisagem, em virtude da maior sensibilização do avaliador.

Devido aos resultados de escolha das duas paisagens da classe baixa como as piores e das duas paisagens da classe alta entre as primeiras posições de preferência visual, pode-se afirmar que houve correlação entre a preferência visual dos entrevistados e a disposição das fotografias em classes de qualidade visual, pela aplicação da metodologia criada para avaliação técnica.

A implantação de edificações em lotes adjacentes ao parque constitui-se em ação desarmônica, depreciando a qualidade visual da paisagem do entorno oeste do Parque Tanguá. No entanto, a percepção das construções, como impacto negativo, está fortemente relacionada com a escala da paisagem, pois se os pontos de observação estivessem mais distanciados, ou seja, numa escala menor, a percepção da interação antrópica com a paisagem seria menor e considerada menos agressiva. Estas constatações demonstram a necessidade de se criar e manter uma Zona de Amortecimento no parque a fim de diminuir a qualificação negativa da paisagem local, principalmente para observações feitas do mirante, que é o ponto principal de visitação localizado na porção de maior elevação topográfica do parque e com melhor visualização do entorno oeste.

\section{CONCLUSÕES}

A valoração da paisagem do Parque Tanguá, por meio da metodologia apresentada, mostrou-se uma técnica muito útil porque possibilitou conhecer os componentes predominantes e aqueles que depreciam a qualidade visual das paisagens do entorno e aquelas internas.

A qualidade visual da paisagem foi influenciada positivamente pelo elemento vegetação arbórea e negativamente pelo componente urbanização.

A partir dos resultados obtidos pode-se concluir que a qualidade visual da paisagem do Parque Tanguá é boa e atrativa, mesmo com as ações antrópicas do entorno oeste imediato.

A análise da preferência do público visitante permitiu constatar que não houve correlação entre o perfil dos entrevistados e a escolha das paisagens apresentadas. Porém

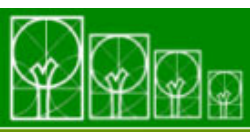

$\mathbf{S} \cdot \mathbf{B} \cdot \mathbf{A} \cdot \mathbf{U}$ Soc. Bras. de Arborização Urbana 
verificou-se que os visitantes preferem paisagens mais heterogêneas, harmônicas e sem o componente urbanização.

Recomenda-se que o entorno oeste do parque, próximo ao seu limite, seja gerenciado com mais critério e cuidado, a fim de se evitar maiores impactos visuais negativos que alteram a qualidade visual da paisagem.

\section{REFERÊNCIAS}

BASTARZ, C. Análise da preferência da paisagem do município de Morretes, Paraná como subsídio ao planejamento do turismo. 122p. Dissertação (Mestrado em Engenharia Florestal) - Setor de Ciências Agrárias, Universidade Federal do Paraná, Curitiba, 2009.

BIONDI, D.; MÓRMUL, M. L. P. Parques urbanos de Curitiba/PR - Qual a preferência de seus usuários. In: VII Encontro Nacional de Ensino de Paisagismo, 7, Belo Horizonte, Anais..., Belo Horizonte: UFMG, 2004.

BLEY, L. Morretes - Estudo de Paisagem Valorizada. 215p. Tese (Doutorado em Geografia) - Instituto de Geociências e Ciências Exatas, Universidade Estadual Paulista, Rio Claro, 1990.

BULUT, Z.; YILMAZ, H. Determination of landscape beauties through visual quality assessment method: a case study for Kemaliye (Erzincan/Turkey). Environmental Monitoring and Assessment, Amsterdam, v. 141, n. 1-3, p.121-129, 2008.

CASTELNOU NETO, A. M. Parques Urbanos de Curitiba: de espaços de lazer a objetos de consumo. Cadernos de Arquitetura e Urbanismo, Belo Horizonte, v. 13, n. 14, p. 53-73, 2006.

CEOTMA. Guia para elaboración de estúdios del medio físico: contenido y metodologia. Serie manuales, 3, $2^{\mathrm{a}}$ ed. Madrid: MOPU, 1984. 572p.

CURITIBA, Prefeitura Municipal de Curitiba. Plano de Manejo do Parque Municipal Tanguá. Curitiba: FUPEF, 2002.

CURITIBA. Parques e Bosques: Parque Tanguá. Disponível em: http://www.curitiba.pr.gov.br/Secretaria. aspx?idf=399\&servico=26. Acesso em 02/02/2008.

GONZAGA, C. A. M.; WANDEMBRUCK, A.; SEGER, C. D.; BIONDI, D. Análise paisagística da trilha recreativa do Parque Municipal do Passaúna. Caderno de Biodiversidade, Curitiba, v. 4, n. 2, p. 66-73, 2004.

IAPAR. Cartas climáticas básicas do Estado do Paraná. Londrina: IAPAR, 1994, 45p.

KAICK, J. A. M. V.; HARDT, L. P. A.; OBA, L. T. Contribuição dos Parques Urbanos e Áreas Verdes como Atrativos Turísticos em Curitiba - Paraná. In: Encontro da ANPPAS, 3, Brasília. Anais..., Brasília: ANPASS, 2006.

KAMICAITYTE-VIRBASIENE, J.; JANUSAITIS, R. Some methodical aspects of Landscape Visual Quality - Preferences Analysis. Environmental research, engineering and management. Kaunas (Lt), v. 29, n. 3, p. 51-60, 2004. 
LUCAS, O. W. R. The Design of Forest Landscape. New York: Oxford University Press, 1991.

MARENZI, R. C. Estudo da Valorização da Paisagem e Preferências Paisagísticas no Município da Penha-SC. 119p. Dissertação (Mestrado em Engenharia Florestal) - Setor de Ciências Agrárias, Universidade Federal do Paraná, Curitiba, 1996.

MARENZI, R. C. A análise da qualidade visual da paisagem como instrumento da ecologia da paisagem. In: Fórum de debates - Ecologia da Paisagem e Planejamento Ambiental, 1, 2000, Rio Claro. Anais...,Rio Claro: SEB, 2000.

MENEZES, C. L. Desenvolvimento urbano e meio ambiente: a experiência de Curitiba. Campinas: Papirus, 1996. 198p.

MILANO, M. S. Estudos da paisagem na avaliação de impactos ambientais. In: Seminário sobre avaliação e Relatório de Impacto Ambiental, 1, 1990, Curitiba. Anais..., Curitiba: FUPEF, 1990. p. 117-125.

OLIVEIRA, D. A. Ecologia e valoração da paisagem no entorno de Paranaguá. 97p. Dissertação (Mestrado em Engenharia Florestal) - Setor de Ciências Agrárias, Universidade Federal do Paraná, Curitiba, 2003.

PIRES, P. S. Avaliação da Qualidade Visual da Paisagem na Região Carbonífera de Criciúma-SC. 72p. Dissertação (Mestrado em Engenharia Florestal) - Setor de Ciências Agrárias, Universidade Federal do Paraná, Curitiba, 1993.

PIRES, P. S. Caracterização e análise visual da paisagem rural com enfoque turístico - uma contribuição metodológica. Turismo-Visão e Ação, Itajaí, v. 4, n. 8, p. 83-97, 2001.

PIRES, P. S. A análise de indicadores da qualidade visual como etapa da caracterização de paisagens turísticas: uma aplicação no distrito-sede de Porto Belo-SC. Turismo-Visão e Ação, Itajaí, v. 7, n. 3, p. 417-426, 2005.

VIEIRA, C. H. S. D.; KOZERA, C. BIONDI, D. Preferência visual de paisagens do Parque Municipal do Passaúna, Curitiba, PR. Paisagem e Ambiente, São Paulo, v. 24, p. 421-430, 2007. 